\title{
Economic Impact of Mirabegron Versus Antimuscarinics for the Treatment of Overactive Bladder in the UK
}

\author{
Jameel Nazir ${ }^{1} \cdot$ Malin Berling $^{2} \cdot$ Charles McCrea $^{3} \cdot$ Francis Fatoye $^{4} \cdot$ \\ Sally Bowditch $^{1} \cdot$ Zalmai Hakimi $^{5} \cdot$ Adrian Wagg $^{6}$
}

Published online: 30 January 2017

(c) The Author(s) 2017. This article is published with open access at Springerlink.com

\begin{abstract}
Purpose Our objective was to estimate the economic outcomes of using mirabegron versus antimuscarinics in the treatment of patients with overactive bladder $(\mathrm{OAB})$ from a societal perspective in the UK.

Materials and Methods A Markov model was developed using Microsoft Excel ${ }^{\circledR}$. The time horizon and cycle length are 12 and 1 months, respectively; and the hypothetical cohort size 100 patients. Antimuscarinic comparators are fesoterodine, oxybutynin extended release (ER) and immediate release (IR), solifenacin, tolterodine ER/IR, trospium ER/IR, darifenacin and flavoxate. Model inputs included real-world treatment patterns data, healthcare resource use (e.g. clinic visits) and direct and indirect costs (e.g. drug acquisition and productivity loss). Model outputs included patient disposition, healthcare resource use, drug
\end{abstract}

Electronic supplementary material The online version of this article (doi:10.1007/s41669-017-0011-x) contains supplementary material, which is available to authorized users.

Jameel Nazir

Jameel.Nazir@astellas.com

Astellas Pharma Europe Ltd, Chertsey KT16 0PS, UK

PAREXEL Access Consulting, Stockholm, Sweden

PAREXEL Access Consulting, London, UK

4 Department of Health Professions, Faculty of Health, Psychology and Social Care, Manchester Metropolitan University, Manchester, UK

5 Astellas Pharma Europe B.V., Leiden, The Netherlands

6 Geriatric Medicine, University of Alberta, Edmonton, AB, Canada acquisition costs and other treatment-related costs over a 1-year time horizon. A one-way sensitivity analysis was performed to determine the key drivers of the model.

Results In a hypothetical cohort of 100 patients, total annual costs per patient were lower with mirabegron than with all antimuscarinics (£1270.84 vs. 1321.71-1607.48). Healthcare resource use was lower with mirabegron than with all antimuscarinics (115 vs. 119-123 general practitioner visits; 173 vs. $178-185$ specialist visits and 0.0042 vs. 0.0050-0.0060 surgical operations) and fewer work hours were lost (4017 vs. 5114-6990 [all per 100 patients]). Sensitivity analysis showed the model was sensitive to persistence and switching rates, although the impact on the overall results was minimal.

Conclusions In the UK, using mirabegron to treat $\mathrm{OAB}$ may improve persistence and lead to reductions in switching treatment, healthcare resource utilization, productivity costs, and overall treatment costs versus antimuscarinics.

\section{Key Points for Decision Makers}

Treatment of overactive bladder $(\mathrm{OAB})$ with mirabegron $50 \mathrm{mg}$ in the UK may result in lower healthcare resource utilization, lost productivity costs, and overall treatment costs compared with antimuscarinics.

Further work is needed to confirm these findings in different populations to assess the effects of mirabegron on the costs of treatment in other countries. 


\section{Introduction}

Overactive bladder $(\mathrm{OAB})$ is characterized by urinary urgency, usually with urinary frequency and nocturia, with or without urinary incontinence [1]. OAB affects up to $17 \%$ of adults aged $\geq 40$ years in Europe and up to $17 \%$ of all adults in the USA $[2,3]$. In Europe, a higher proportion (30-40\%) of OAB is observed in adults $\geq 75$ years of age [2].

The clinical and economic burden of $\mathrm{OAB}$ is significant. Symptoms of OAB have been reported to adversely affect patients' daily activities, sleep, mental health and personal

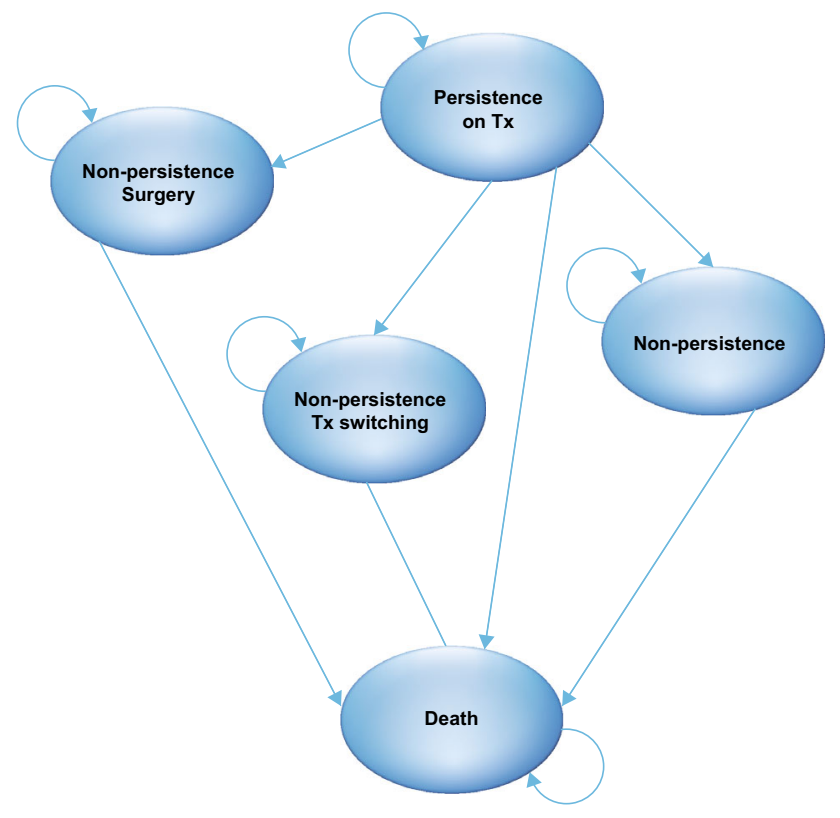

Fig. 1 Markov model structure $t x$ treatment relationships [4, 5]. These symptoms also have a significant impact on productivity in the workplace and healthcare resource use [6]. In the UK, the total direct economic impact (incremental costs) of $\mathrm{OAB}$ on the national healthcare system is estimated to be in excess of $£ 1$ billion [6].

Following the use of conservative management strategies, treatment with pharmacotherapy can result in symptom improvement. However, bothersome on-treatment adverse events (AEs) from antimuscarinic agents (such as dry mouth and constipation) are common because of a lack of target organ specificity [7]. Side effects observed with antimuscarinics may also have deleterious effects on treatment persistence. A screening survey conducted in the USA identified 6577 patients with one or more antimuscarinic prescriptions for $\mathrm{OAB}$ [8]. Of the 1322 patients who reported discontinuing treatment prior to follow-up, 1177 (89\%) discontinuations were primarily due to unmet treatment expectations and/or tolerability [8].

Mirabegron is a first-in-class licensed selective oral $\beta_{3^{-}}$ adrenoceptor agonist approved in the UK for the treatment of OAB [9]. It promotes bladder relaxation of the detrusor muscle during the storage phase, improving bladder capacity [10]. Mirabegron demonstrated overall efficacy similar to that of antimuscarinic therapies in clinical trials [11] but with an improved overall tolerability profile $[11,12]$. Evidence from a recent retrospective analysis of prescription claims in Canada demonstrated that, over a 12-month period, patients with $\mathrm{OAB}$ treated with mirabegron have improved persistence compared with those treated with antimuscarinics [13].

A prospective study of women with $\mathrm{OAB}$ who received treatment with fesoterodine for 8 weeks also showed that those who adhered to treatment reported significantly

Fig. 2 Treatment pathway

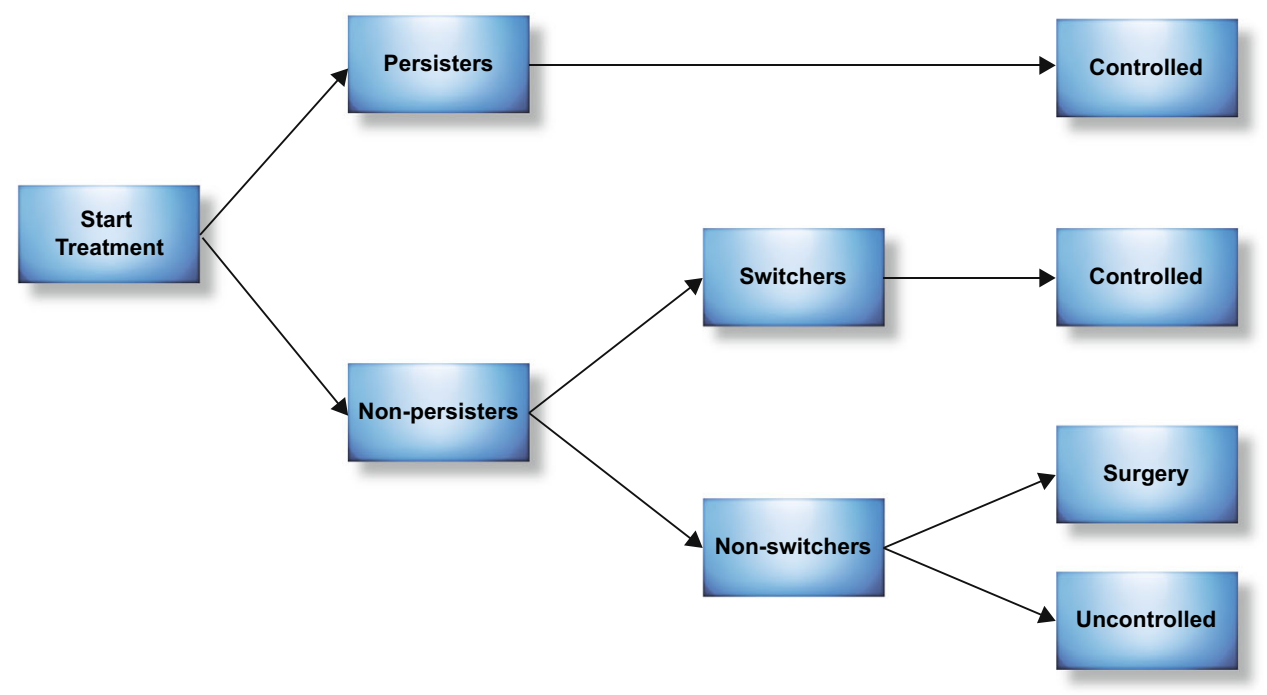


greater improvements in clinical symptoms at the end of the treatment period than those who were non-adherent [14]. In addition, persistence with treatment has been shown to reduce consumption of healthcare resources in $\mathrm{OAB}$ [15]. Given the impact of OAB on work absenteeism and productivity [6], persistence and symptom control may be expected to reduce the impact of these factors.

This study aimed to use predominantly real-world evidence to estimate the economic outcomes associated with persistence with mirabegron treatment versus antimuscarinic agents in patients with $\mathrm{OAB}$ in the UK.

\section{Methods}

\subsection{Model Overview}

This is a Microsoft ${ }^{\circledR}$ Excel-based (version 17.0, Microsoft Corporation, Redmond, WA, USA) Markov model. The time horizon is 12 months, the cycle length is 1 month and the default cohort size is 100 patients. Mirabegron $50 \mathrm{mg} /$ day is compared with the following antimuscarinic treatments (all doses reported are per day): fesoterodine 4/8 mg, oxybutynin extended release (ER) $5 \mathrm{mg}$, oxybutynin immediate release (IR) $5 \mathrm{mg}$, solifenacin $5 / 10 \mathrm{mg}$,

Table 1 Model assumptions

Non-persisters were assumed to either switch, undergo surgical operations or remain uncontrolled

Switchers and patients having surgical operations were assumed to have controlled symptoms

At treatment initiation (the start of the model), all patients were assumed to incur one visit to a GP and 1.5 visits to a specialist (urologist) [17]

Switchers were assumed to have one GP visit, 1.5 visits to a specialist (urologist) and one urodynamic test [17]

Patients who switched treatment were ascribed a drug acquisition cost, which was weighted by the market share of each treatment. The market share data were provided by Astellas [24]

One total probability of surgical operations was included and costs were applied [19], assuming that 50\% of patients had onabotulinumtoxinA injection and $50 \%$ had SNS

Only non-persisters with uncontrolled symptoms were assumed to be at risk of co-morbidities (depression and UTI) [25]; the risk was applied in each cycle

Patients who were non-persistent and uncontrolled were assumed to have a $21.1 \%$ decrease in hours worked [25]

The persistence at 12 months was assumed to be the same for each treatment irrespective of the dose received [16]

The persistence at 12 months was assumed to be the same for trospium ER and IR formulations, and tolterodine ER and IR [16]

$E R$ extended release, $G P$ general practitioner, $I R$ immediate release, $S N S$ sacral nerve stimulation, $U T I$ urinary tract infection

Table 2 Clinical inputs

\begin{tabular}{lll}
\hline Variable & Value $(\%)$ & Source \\
\hline Proportion of patients with incontinence & 60.00 & Nitti et al. [22] \\
Percentage of patients switching treatment & 26.06 & Nazir et al. [17] \\
12-month persistence (UK CPRD) & & \\
Mirabegron 50 mg & 37.70 & Astellas [16] \\
Fesoterodine $4 / 8 \mathrm{mg}$ & 24.00 & Astellas [16] \\
Oxybutynin ER 5 mg & 17.20 & Astellas [16] \\
Oxybutynin IR 5 mg & 12.40 & Astellas [16] \\
Solifenacin 5/10 mg & 24.80 & Astellas [16] \\
Tolterodine ER 4 mg & 20.60 & Astellas [16] \\
Tolterodine IR $4 \mathrm{mg}$ & 20.60 & Astellas [16] \\
Trospium ER 60 mg & 19.10 & Astellas [16] \\
Trospium IR 40 mg & 19.10 & Astellas [16] \\
Darifenacin 7.5 mg & 15.90 & Astellas [16] \\
Flavoxate 600 mg & 8.30 & Astellas [16] \\
General population mortality & 0.97 & ONS [18] \\
\hline
\end{tabular}

$C P R D$ Clinical Practice Research Datalink, ER extended release, IR immediate release, ONS Office for National Statistics

a A conservative estimate of $60 \%$ was applied to the model based on $65.7 \%$ of the total population who were reported to have urgency or mixed incontinence at baseline. All doses reported are the total dose per day 
tolterodine ER or IR both $4 \mathrm{mg}$, trospium ER $60 \mathrm{mg}$ or IR $40 \mathrm{mg}$, darifenacin $7.5 \mathrm{mg}$, and flavoxate $600 \mathrm{mg}$.

The base-case analysis provided a societal perspective of OAB management by accounting for all costs incurred by the UK NHS as well as those associated with lost productivity. Patient disposition, healthcare resource use, direct costs, indirect costs and total costs were all assessed as part of the base-case analysis.

\subsection{Treatment Pathway}

Patients enter the model in the 'persistence on treatment' health state (Fig. 1) and are assigned to treatment with mirabegron $50 \mathrm{mg}$ (the recommended approved dose in the UK [9]) or an antimuscarinic agent (Fig. 2). At the end of each month, patients either persist with treatment or discontinue. Those who discontinue initial treatment switch to an alternative pharmacological intervention, undergo surgical operations (onabotulinumtoxinA injection or sacral nerve stimulation $[\mathrm{SNS}]$ ) or discontinue treatment altogether. Patients can transition to other treatment states or death at each cycle. To make the analysis tractable within a 12-month time horizon, the model assumes that switching to a second-line pharmacotherapy and undergoing surgical operations both lead to symptom control (with no option for additional lines of treatment) until the end of the time horizon. Patients who discontinue treatment altogether are assumed to

Table 3 Resource inputs

\begin{tabular}{|c|c|c|c|}
\hline Parameter & Value or probability & Unit cost & Source \\
\hline Drug acquisition & & Cost per day $(\mathfrak{f})$ & \\
\hline First-line pharmacotherapy & - & & \\
\hline Mirabegron $50 \mathrm{mg}$ & - & 0.97 & BNF $71[23]$ \\
\hline Fesoterodine $4 / 8 \mathrm{mg}$ & - & 0.92 & BNF $71[23]$ \\
\hline Oxybutynin ER $5 \mathrm{mg}$ & - & 0.46 & BNF 71 [23] \\
\hline Oxybutynin IR $5 \mathrm{mg}$ & - & 0.07 & BNF $71[23]$ \\
\hline Solifenacin $5 / 10 \mathrm{mg}^{\mathrm{a}}$ & - & 1.00 & BNF $71[23]$ \\
\hline Tolterodine ER $4 \mathrm{mg}$ & - & 0.92 & BNF $71[23]$ \\
\hline Tolterodine IR $4 \mathrm{mg}$ & - & 0.09 & BNF $71[23]$ \\
\hline Trospium ER $60 \mathrm{mg}$ & - & 0.82 & BNF $71[23]$ \\
\hline Trospium IR $40 \mathrm{mg}$ & - & 0.83 & BNF $71[23]$ \\
\hline Darifenacin $7.5 \mathrm{mg}$ & - & 0.91 & BNF $71[23]$ \\
\hline Flavoxate $600 \mathrm{mg}$ & - & 0.39 & BNF $71[23]$ \\
\hline Second-line pharmacotherapy ${ }^{b}$ & - & 0.64 & BNF 71 [23], Astellas [24] \\
\hline Surgical operations ${ }^{c}$ & $0.01 \%$ & 1242.59 & \\
\hline \multicolumn{4}{|l|}{ Visits/test } \\
\hline GP & 1 & 46.89 & Nazir et al. [19]; PSSRU [21] \\
\hline Urologist & 1.5 & 102.16 & Nazir et al. [19]; UK Department of Health \\
\hline Urodynamic test & 1 & 282.00 & Nazir et al. [19]; South Devon Healthcare [30 \\
\hline Pads & & Cost per pad (f) & \\
\hline On treatment & 2.5/day & 0.25 & Nazir et al. [19]; Incontinence Direct [31] \\
\hline Off treatment & 5.5/day & 0.25 & Nazir et al. [19]; Incontinence Direct [31] \\
\hline \multicolumn{4}{|l|}{ Co-morbidities } \\
\hline Depression & $19.0 \%{ }^{\mathrm{d}}$ & 99.10 & Arlandis-Guzman et al. [25]; Irwin et al. [6] \\
\hline UTI & $30.7 \%^{\mathrm{d}}$ & 2.79 & Arlandis-Guzman et al. [25]; Irwin et al. [6] \\
\hline
\end{tabular}

All doses reported are the total dose per day

$B N F$ British National Formulary, ER extended release, GP general practitioner, $I R$ immediate release, $O A B$ overactive bladder, $U T I$ urinary tract infection

${ }^{\text {a }}$ Weighted average of solifenacin $5 \mathrm{mg}(70 \%)$ and $10 \mathrm{mg}(30 \%)$; unit costs of 30 tablet packs of $£ 27.62$ and $£ 35.91$, respectively

b Weighted cost based on market share of oral therapies for $\mathrm{OAB}$

${ }^{c}$ Weighted cost based on a 50:50 ratio of onabotulinumtoxinA and sacral nerve stimulation

d 6-month probability; unit costs based on 2005 monthly costs, converted to 2015 values using the UK forex exchange rate (as of October 2015) 
remain uncontrolled. Other model assumptions are reported in Table 1.

\subsection{Model Input Parameters}

\subsubsection{Clinical Inputs}

We derived 12-month persistence data (Table 2) from a retrospective database study conducted in the UK [16]. In addition, the treatment switching rate $(26.06 \%)$ was taken from a previously published cost-effectiveness analysis of mirabegron compared with antimuscarinics for the treatment of adults with OAB in the UK [17]. Mortality for the population with OAB was based on the UK age-standardized general population mortality rate [18] and converted to a 1-month probability $(P)$ using the formula: $P=1-\mathrm{e}^{-r t}$, where $r$ represents rate and $t$ time.

\subsubsection{Healthcare Resource Use}

Costs associated with resource use such as general practitioner (GP) and specialist visits were derived from NHS data [19-21]. Unit costs were calculated/estimated for one GP visit and 1.5 referrals to a urologist at treatment initiation and treatment switch (Table 3) [17]. One test by a specialist clinician (e.g. urologist, gynaecologist or other) was performed for each patient who switched to a secondline pharmacotherapy [17]. The proportion of patients with incontinence and requiring pads was estimated to be $60 \%$ based on the number of patients with wet OAB [22]. Pad use was estimated to be 2.5 pads per day for patients on treatment (i.e. persisters and switchers) and 5.5 pads per day for those off treatment (i.e. those who underwent surgical operations or discontinued all treatment) [19].

Drug acquisition costs were calculated based on the treatment cost per pack (Table 3) [23] and were correct as of quarter 1, 2016. The cost of second-line pharmacotherapy was based on a weighted average derived from UK market share data [24].

Patients who were uncontrolled were considered to be at risk of two co-morbidities: depression and urinary tract infection (UTI). The 6-month probabilities of depression and UTI were 18.8 and $30.7 \%$, respectively [25], and the monthly probability of surgical operations was $0.01 \%$ [17].

The costs for all resources were based on 2015 values, or inflated to 2015 values using the consumer price index (CPI) where applicable. The costs of depression and UTI sourced from Irwin et al. [6] were converted from $€$ to British £ using the UK Forex exchange rate (as of December 2015).

\subsubsection{Loss of Productivity}

The model accounts for loss of work productivity only in patients who are non-persistent with treatment, have uncontrolled symptoms and are in employment. The basecase analysis assumed that $34.7 \%$ of the patients were employed for an average of $40 \mathrm{~h}$ per week [25, 26], had uncontrolled $\mathrm{OAB}$ and had a $21.1 \%$ reduction in the hours worked [25]. The average hourly wage of $£ 12.62$ (2011 value) was inflated to $£ 13.94$ (2015 value) using the CPI [27].

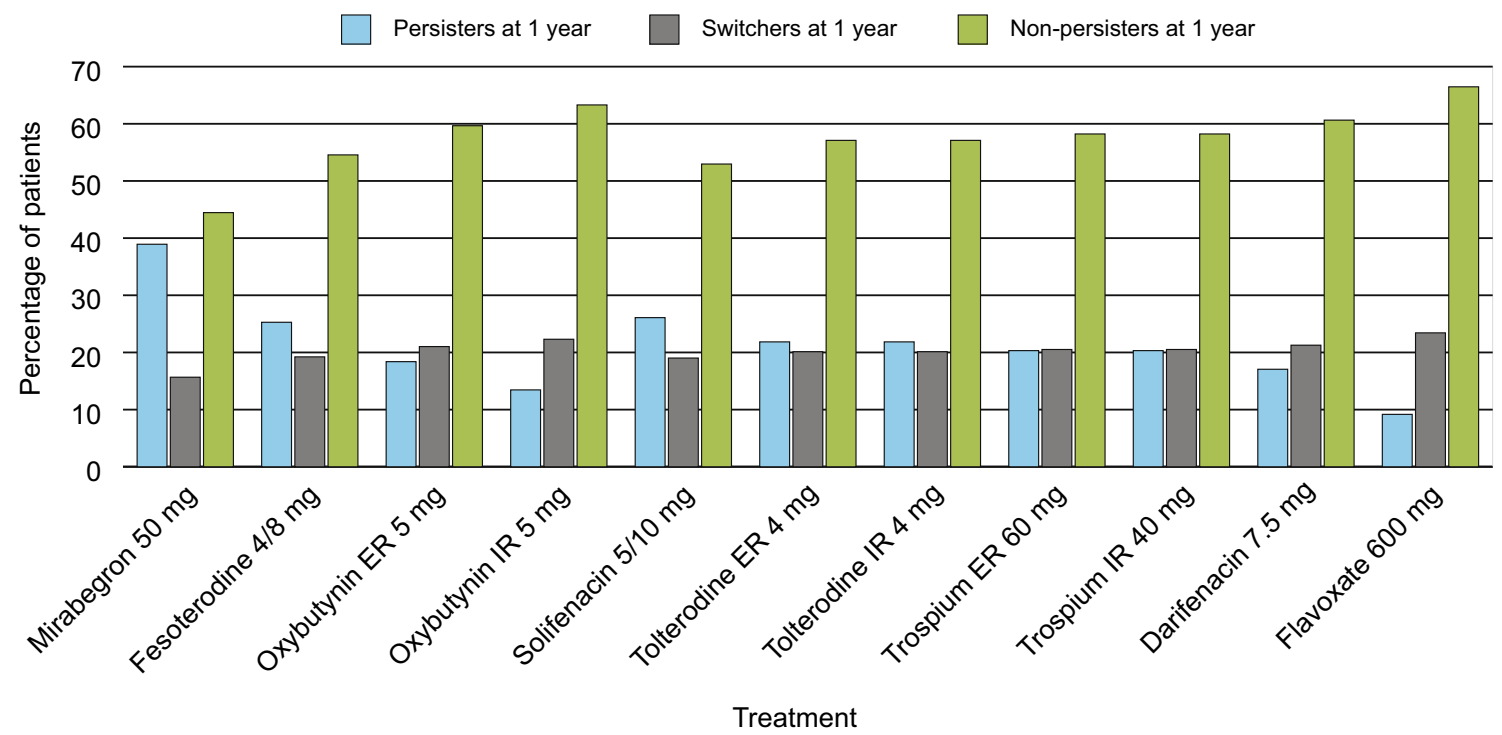

Fig. 3 Summary of patient disposition after 12 months for each treatment. Total disposition may not sum to $100 \%$ because of rounding. All doses reported are the total dose per day. $E R$ extended release, $I R$ immediate release 


\subsection{Sensitivity Analysis}

A one-way univariate deterministic sensitivity analysis (DSA) was performed to assess the uncertainty of chosen parameters [28]. Here, a standard $20 \%$ variation in the following model parameters was tested individually and the effects on the incremental costs determined: persistence at 12 months, percentage of patients switching and probability of surgical operations. Mirabegron $50 \mathrm{mg}$ was compared with solifenacin $5 / 10 \mathrm{mg}$ and oxybutynin IR $5 \mathrm{mg}$. The results of the DSA were presented as a tornado diagram, with the parameters that had the greatest impact at the top.

\section{Results}

\subsection{Patient Disposition}

After 12 months, more patients persisted on treatment with mirabegron $50 \mathrm{mg}$ than with all antimuscarinics (39 vs. 9-26\%, respectively [values for all antimuscarinics presented as a range]) (Fig. 3). This resulted in fewer patients either switching treatment (16 vs. 19-23\%, respectively) or becoming non-persistent uncontrolled patients (44 vs. 54-66\%, respectively).

\subsection{Healthcare Resources}

Resource use was lower with mirabegron $50 \mathrm{mg}$ than with all antimuscarinics, including GP visits (115 vs. 119-123, respectively, per 100 patients), specialist visits (173 vs. 178-185, respectively, per 100 patients) and number of surgical operations $(0.0042$ vs. $0.0050-0.0060$, respectively, per 100 patients) (Table 4). Total pad use per patient over 12 months was also lower with mirabegron $50 \mathrm{mg}$ than with all antimuscarinics $(71,807$ vs. 76,531-84,602, respectively, per 100 patients) (Fig. 4).

\subsection{Direct Costs}

Mirabegron $50 \mathrm{mg}$ had a higher medication cost than all antimuscarinics (£24,744 vs. 4599-22,634 per 100 patients) (Table 5). However, resource use costs, including those for the co-morbidities of depression and UTI, GP visits, specialist visits, surgical operations, urodynamic tests and pads, were lower with mirabegron than with all antimuscarinics (Table 5).

\subsection{Indirect Costs}

The number of work hours lost (4017 vs. 5114-6990 per 100 patients) and the cost due to work hours lost (£55,983

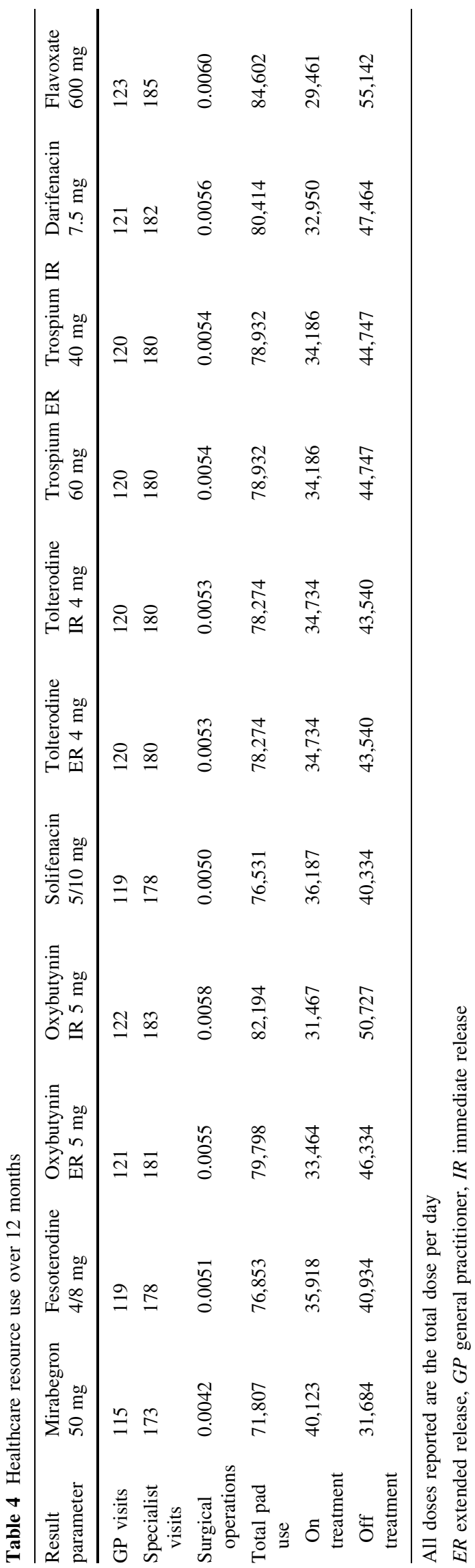




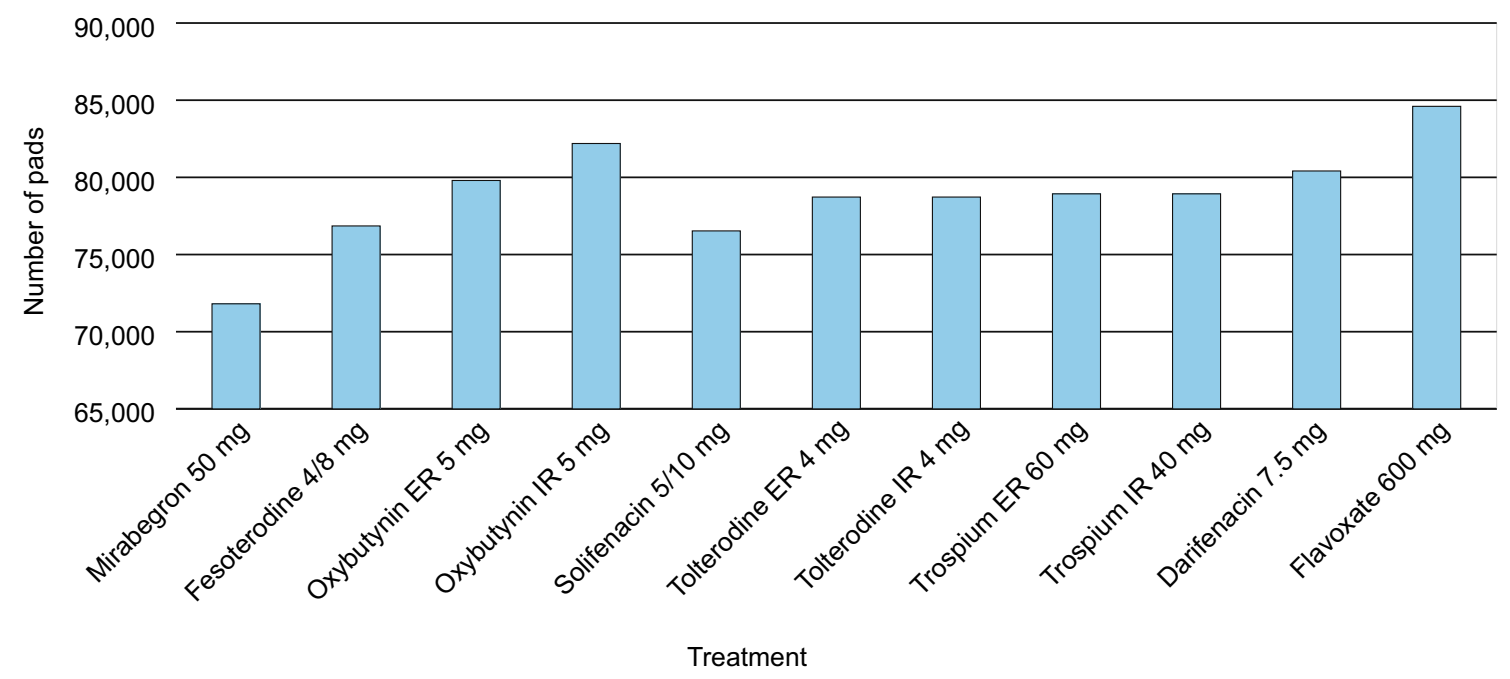

Fig. 4 Total pad use per 100 patients, after 12 months for each treatment. All doses reported are the total dose per day. ER extended release, $I R$ immediate release

vs. 71,284-97,430 per 100 patients) were both lower with mirabegron $50 \mathrm{mg}$ than with all antimuscarinics (Fig. 5).

\subsection{Total Costs}

Total costs were lower for mirabegron $50 \mathrm{mg}$ than for all antimuscarinics ( $£ 127,084$ vs. $132,171-160,748$, respectively, per 100 patients) (Fig. 6). This translated into lower respective total costs per patient ( $£ 1271$ vs. $1322-1607$ ) and per patient per day ( $£ 3.48$ vs. $3.62-4.40$ ).

\subsection{Sensitivity Analysis}

For both comparisons, the model was most sensitive to $\pm 20 \%$ changes in persistence rates for either treatment and the percentage of patients switching (Fig. 7). The incremental cost savings per patient per day were $-£ 0.45$ in the base-case analysis of mirabegron $50 \mathrm{mg}$ versus solifenacin $5 / 10 \mathrm{mg}$ and $-£ 0.55$ versus oxybutynin IR $5 \mathrm{mg}$. The overall impact was similar when the incremental cost savings per additional patient persisting on treatment were assessed (Fig. S1 in the Electronic Supplementary Material).

\section{Discussion}

To our knowledge, this model is the first to estimate the economic impact of using mirabegron $50 \mathrm{mg}$ versus antimuscarinic agents for the treatment of $\mathrm{OAB}$ from a societal perspective in the UK, largely employing realworld data (specifically persistence rates).

According to the model, after 12 months, more patients receiving mirabegron $50 \mathrm{mg}$ versus all antimuscarinics persisted with treatment, fewer patients switched treatment and fewer work hours were lost. Although mirabegron $50 \mathrm{mg}$ had higher medication costs over 12 months than did antimuscarinics, these costs were offset by savings attributed to other direct and indirect costs. This was partly attributable to a lower proportion of non-persisters and switchers, who had higher demand for healthcare resources and higher pad use than patients who persisted with treatment. The results suggest that more patients in the UK who receive mirabegron will persist with first-line pharmacological treatment versus antimuscarinics over 12 months, resulting in more patients with likely controlled symptoms. Administration of mirabegron as first-line pharmacotherapy for $\mathrm{OAB}$ could have beneficial effects in terms of lower resource use and overall treatment, containment of healthcare costs and societal benefit. Furthermore, while lower healthcare resource use has been cited as a benefit of increased treatment persistence [15], better persistence rates could also be expected to improve patient quality of life (QoL), likely because of increased symptom control and an increased ability to continue daily activities [15]. This model did not include the likely improvements in QoL for those who persist with treatment.

While similar efficacy is observed between mirabegron and antimuscarinics [11], real-world evidence indicates that a higher proportion of patients are likely to be nonpersistent with treatment with antimuscarinics versus mirabegron $50 \mathrm{mg}$ [13]. Potential reasons for treatment discontinuation with antimuscarinics include bothersome AEs such as dry mouth and constipation, the most common AEs in these patients [7]. A recent systematic literature review and network meta-analysis of mirabegron $50 \mathrm{mg}$ versus antimuscarinics in 27,309 patients with $\mathrm{OAB}$ reported a similar incidence of dry mouth for mirabegron $50 \mathrm{mg}$ and 


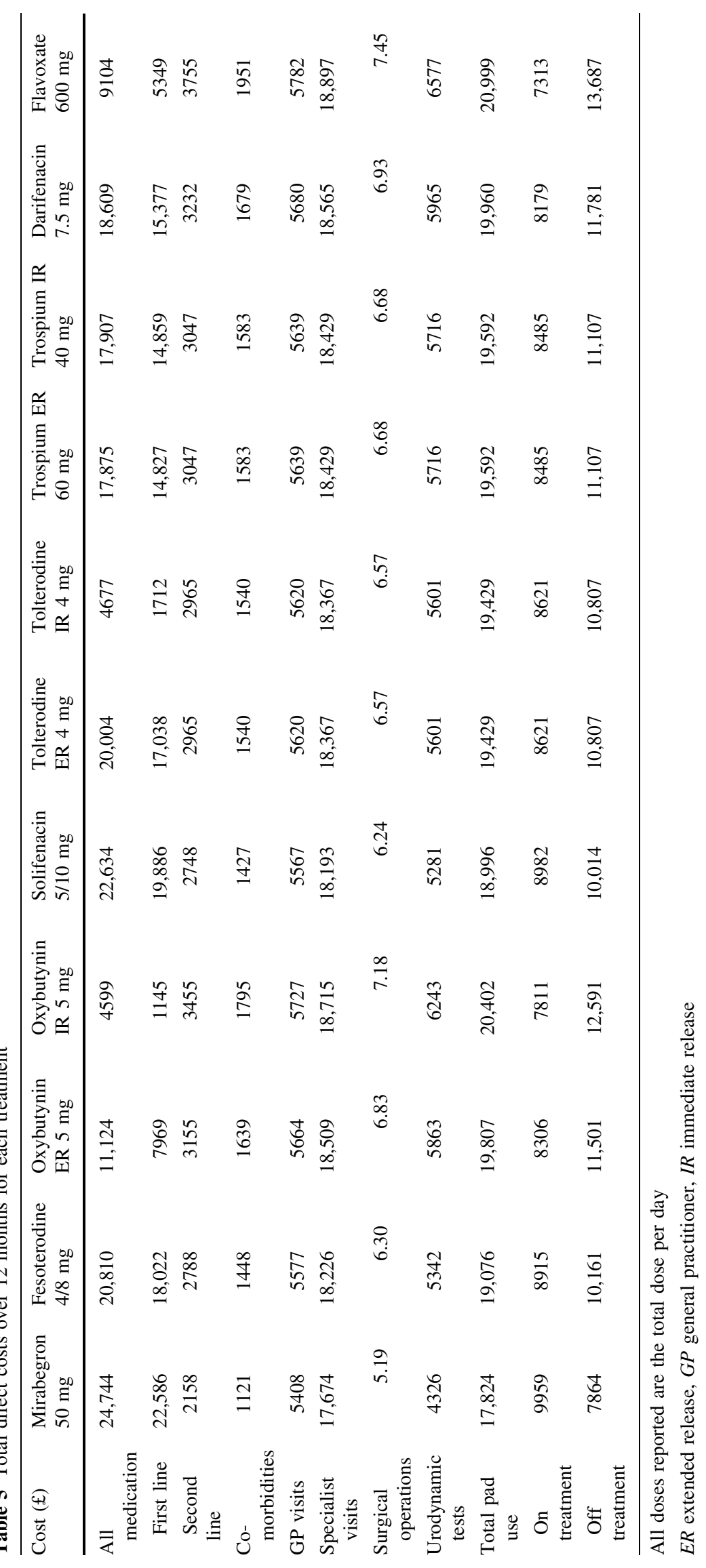




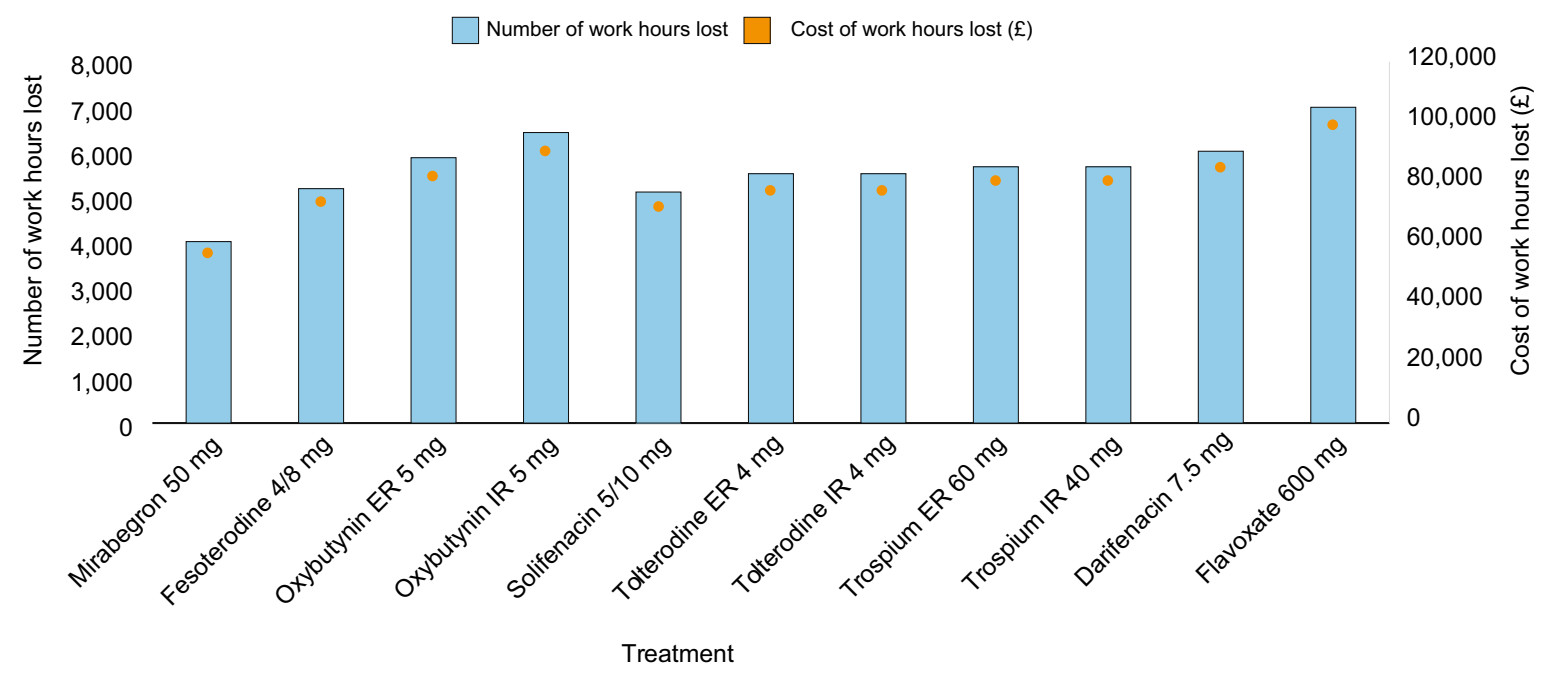

Fig. 5 Total work hours lost over 12 months and associated costs for each treatment per 100 patients. All doses reported are the total dose per day. $E R$ extended release, $I R$ immediate release

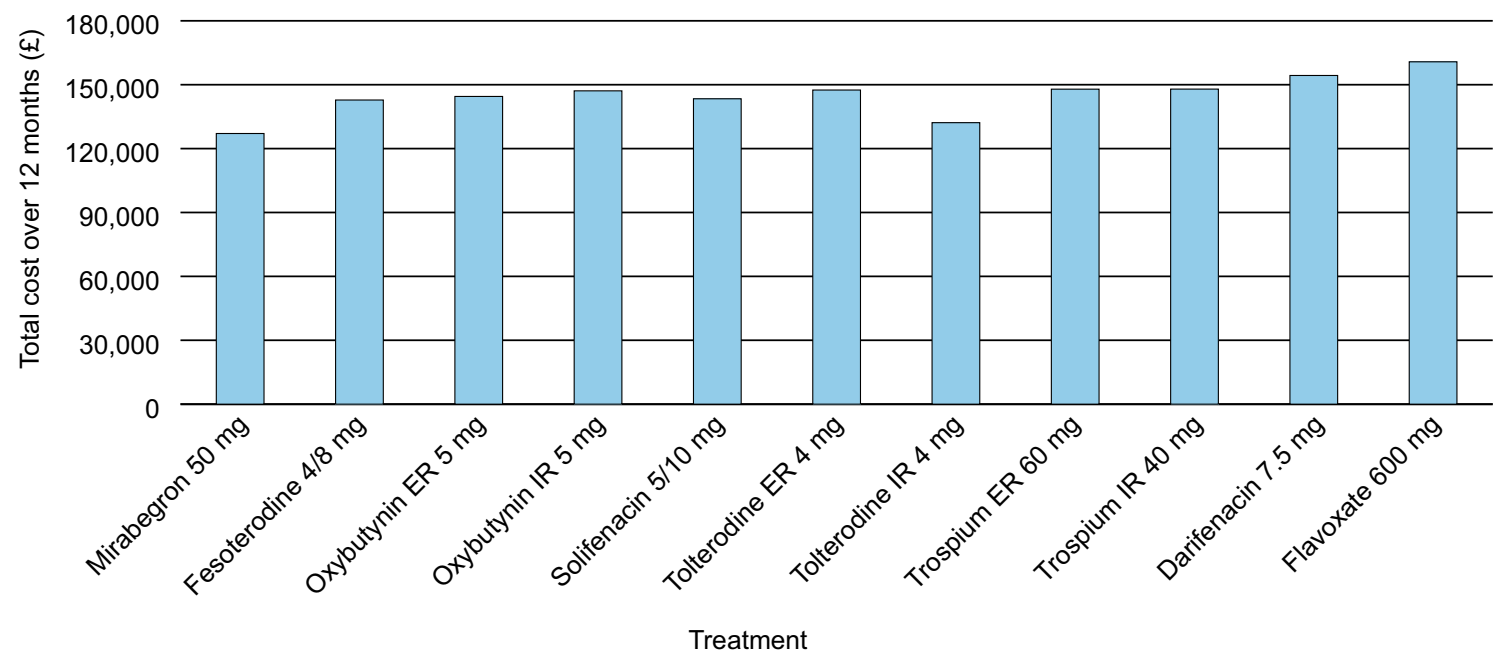

Fig. 6 Total costs (including indirect costs) over 12 months for each treatment per 100 patients. All doses reported are the total dose per day. ER extended release, $I R$ immediate release

placebo but a lower incidence for mirabegron $50 \mathrm{mg}$ versus all antimuscarinics assessed [11]. These findings may be reflected in the present study, as healthcare resource use was lower for mirabegron $50 \mathrm{mg}$ than for all antimuscarinics, with fewer associated costs. However, it should be noted that treatment discontinuation can be attributed to many factors, and a greater overall focus should be applied to tailoring $\mathrm{OAB}$ treatment to the individual.

The primary strengths of this model are that it utilizes real-world data related to treatment of OAB and healthcare resource use in the UK. Therefore, the total costs derived for mirabegron versus antimuscarinics are based on effectiveness rather than efficacy. However, the findings that suggest a benefit of mirabegron (if used as first-line pharmacotherapy for $\mathrm{OAB}$ ) depend on the several key assumptions made in the model, such as persistence at 12 months being independent of the treatment dose received and persistence not varying between trospium ER and IR and tolterodine ER and IR. Furthermore, all patients who switch treatment or undergo surgical operations are assumed to have controlled symptoms, and this would be variable. Structural edits to the model would be required to account for these factors if additional sensitivity analyses were to be performed. As $\mathrm{OAB}$ is a chronic condition, provision of a longer time horizon would be beneficial to accurately estimate the economic benefits of long-term treatment. Another limitation is that no direct clinical data for estimates of efficacy, tolerability or health-related QoL were included; therefore, some patient perspectives were not captured. With respect to the treatment comparators, 


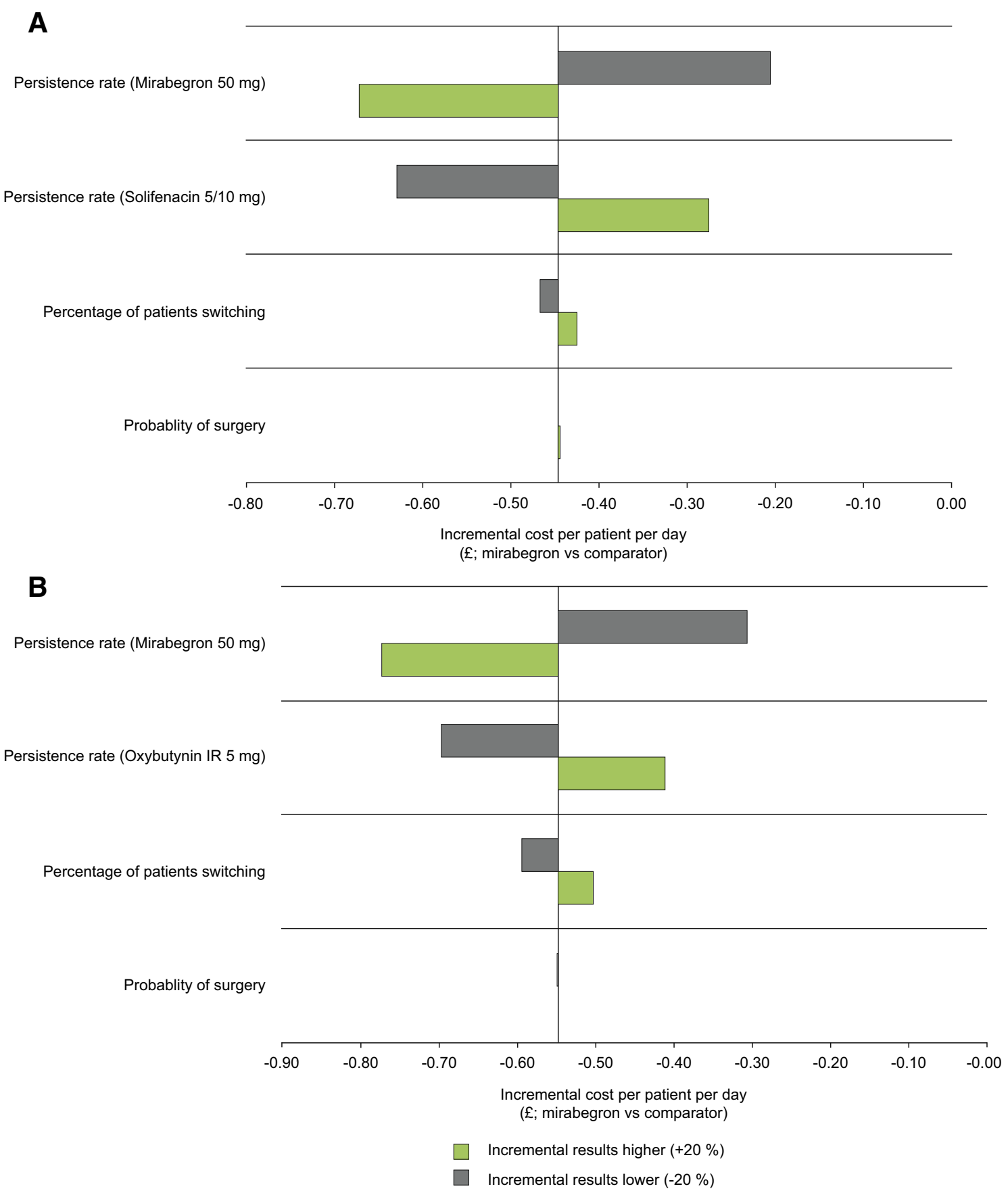

Fig. 7 Results of the deterministic sensitivity analysis for mirabegron $50 \mathrm{mg}$ versus a solifenacin $5 / 10 \mathrm{mg}$ and b oxybutynin IR $5 \mathrm{mg}$ (incremental cost per patient per day). All doses reported are the total dose per day. $I R$ immediate release

the model includes the most common treatment options for $\mathrm{OAB}$ in the UK according to the results of a retrospective analysis of a clinical practice database [16]; this included flavoxate, which is not recommended for use in women with urinary incontinence in the UK [29].

Although the model does not account for persistence in different subgroups of patients, results were largely consistent with the total study population, and few differences in persistence between subgroups were observed in a
Canadian study of persistence with mirabegron $50 \mathrm{mg}$ versus antimuscarinics over 12 months (the only notable difference was that patients were more likely to persist as the number of co-existing prescribed medications increased [up to more than eight]) [13]. Whether differences between subgroups would be observed if the model were updated to allow these kinds of analyses is unclear. The persistence data used in the model were taken from a large non-interventional study conducted in the UK [16]; 
patient demographics in this study were generally wellbalanced across treatment groups, although significantly more patients receiving mirabegron were female, treatment-experienced and receiving co-existing medications compared with those receiving the primary comparator treatment (tolterodine ER).

\section{Conclusions}

This model suggests that treatment of OAB in the UK with mirabegron $50 \mathrm{mg}$ will result in more patients persisting with treatment and lower total costs of treatment versus antimuscarinics. Further work is needed to confirm these findings in different populations to assess the effect of mirabegron on persistence and overall treatment costs in other countries.

Acknowledgements PAREXEL Access Consulting developed the model, funded by Astellas Pharma Europe Ltd. Medical writing support was provided by David Griffiths of Bioscript Medical, funded by Astellas Pharma Global Development.

Author contributions Conception and design: JN, MB, CMc, SB, $\mathrm{ZH}$. Acquisition of data: JN, MB, CMc. Analysis and interpretation of the data: JN, MB, CMc, FF, SB, ZH, AW. Drafting of the manuscript: $\mathrm{JN}, \mathrm{MB}, \mathrm{CMc}, \mathrm{FF}, \mathrm{SB}, \mathrm{ZH}, \mathrm{AW}$. Critical revision of the manuscript for important intellectual content: JN, MB, CMc, FF, SB, ZH, AW. Statistical analysis and modelling: JN, MB, CMc. Obtaining funding: $\mathrm{JN}, \mathrm{SB}, \mathrm{ZH}$.

\section{Compliance with Ethical Standards}

Conflict of interest AW received research grants from Astellas Pharma Europe Ltd, Pfizer Inc. and the Canadian Urological Association. He also received consulting fees or honoraria from SCA, Astellas Pharma Europe Ltd, Pfizer Inc. and Duchesnay Inc. MB and $\mathrm{CMc}$ received consulting fees from Astellas Pharma Europe Ltd for developing the model as part of the PAREXEL team. FF received grant funding from Astellas Pharma Europe Ltd. JN, SB and ZH are employees of Astellas Pharma Europe Ltd. No research involved human participants and/or animals, and no informed consent was required.

Data availability The datasets generated and/or analysed during the current study are not publically available because the model is proprietary. However, all appropriate data generated or analysed during this study are included in this published article and its supplementary information files.

Open Access This article is distributed under the terms of the Creative Commons Attribution-NonCommercial 4.0 International License (http://creativecommons.org/licenses/by-nc/4.0/), which permits any noncommercial use, distribution, and reproduction in any medium, provided you give appropriate credit to the original author(s) and the source, provide a link to the Creative Commons license, and indicate if changes were made.

\section{References}

1. Abrams P, Cardozo L, Fall M, Griffiths D, Rosier P, Ulmsten U, et al. The standardisation of terminology in lower urinary tract function: report from the standardisation sub-committee of the International Continence Society. Urology. 2003;61(1):37-49.

2. Milsom I, Abrams P, Cardozo L, Roberts RG, Thüroff J, Wein AJ. How widespread are the symptoms of an overactive bladder and how are they managed? A population-based prevalence study. BJU Int. 2001;87(9):760-6.

3. Stewart WF, Van Rooyen JB, Cundiff GW, Abrams P, Herzog AR, Corey R, et al. Prevalence and burden of overactive bladder in the United States. World J Urol. 2003;20(6):327-36.

4. Brown JS, McGhan WF, Chokroverty S. Comorbidities associated with overactive bladder. Am J Manag Care. 2000;6(11 Suppl):S574-9.

5. Abrams P, Kelleher CJ, Kerr LA, Rogers RG. Overactive bladder significantly affects quality of life. Am J Manag Care. 2000;6(11 Suppl):S580-90.

6. Irwin DE, Mungapen L, Milsom I, Kopp Z, Reeves P, Kelleher C. The economic impact of overactive bladder syndrome in six Western countries. BJU Int. 2009;103(2):202-9.

7. Lucas MG, Bedretdinova D, Berghmans, LC, Bosch JLHR, Burkhard FC, Cruz F, et al. Guidelines on urinary incontinence. http://uroweb.org/wp-content/uploads/20-Urinary-Incontinence LR1.pdf/. Accessed 16 May 2016.

8. Benner JS, Nichol MB, Rovner ES, Jumadilova Z, Alvir J, Hussein M. Patient-reported reasons for discontinuing overactive bladder medication. BJU Int. 2010;105(9):1276-82.

9. European Medicines Agency. Betmiga EPAR Product Information. http://www.ema.europa.eu/ema/index.jsp?curl=pages/medicines/ human/medicines/002388/human_med_001605.jsp\&mid=WC0b01 ac058001d124/. Accessed 17 Aug 2016.

10. Sacco E, Bientinesi R. Mirabegron: a review of recent data and its prospects in the management of overactive bladder. Ther Adv Urol. 2012;4(6):315-24.

11. Maman K, Aballea S, Nazir J, Desroziers K, Neine ME, Siddiqui E, et al. Comparative efficacy and safety of medical treatments for the management of overactive bladder: a systematic literature review and mixed treatment comparison. Eur Urol. 2014;65(4):755-65.

12. Nitti VW, Chapple CR, Walters C, Blauwet MB, Herschorn S, Milsom I, et al. Safety and tolerability of the beta3-adrenoceptor agonist mirabegron, for the treatment of overactive bladder: results of a prospective pooled analysis of three 12-week randomised Phase III trials and of a 1-year randomised Phase III trial. Int J Clin Pract. 2014;68(8):972-85.

13. Wagg A, Franks B, Ramos B, Berner T. Persistence and adherence with the new beta- 3 receptor agonist, mirabegron, versus antimuscarinics in overactive bladder: early experience in Canada. Can Urol Assoc J. 2015;9(9-10):343-50.

14. Andy UU, Arya LA, Smith AL, Propert KJ, Bogner HR, Colavita $\mathrm{K}$, et al. Is self-reported adherence associated with clinical outcomes in women treated with anticholinergic medication for overactive bladder? Neurourol Urodyn. 2015;35(6):738-42.

15. Kim TH, Lee KS. Persistence and compliance with medication management in the treatment of overactive bladder. Investig Clin Urol. 2016;57(2):84-93.

16. Astellas. Mirabegron vs antimuscarinics in OAB: retrospective analysis of a UK general practice prescription database. Data on file. 2016.

17. Nazir J, Maman K, Neine ME, Briquet B, Odeyemi IA, Hakimi Z, et al. Cost-effectiveness of mirabegron compared with 
antimuscarinic agents for the treatment of adults with overactive bladder in the United Kingdom. Value Health. 2015;18(6):783-90.

18. Office for National Statistics. Mortality statistics: Deaths registered in the UK by areas of usual residence. http://www.ons.gov. uk/ons/rel/vsob1/deaths-registered-area-usual-residence/2014/ index.html/. Accessed 17 May 2016.

19. Nazir J, Posnett J, Walker A, Odeyemi IA, Hakimi Z, Garnham A. Economic evaluation of pharmacological treatments for overactive bladder from the perspective of the UK National Health Service. J Med Econ. 2015;18(5):390-7.

20. National Health Service. NHS reference costs 2014 to 2015. https:// www.gov.uk/government/publications/nhs-reference-costs-2014to-2015/. Accessed 1 July 2016.

21. Personal Social Services Research Unit (PSSRU). Unit costs of health and social care 2014. http://www.pssru.ac.uk/projectpages/unit-costs/2014/. Accessed 1 July 2016.

22. Nitti VW, Khullar V, van Kerrebroeck P, Herschorn S, Cambronero J, Angulo JC, et al. Mirabegron for the treatment of overactive bladder: a prespecified pooled efficacy analysis and pooled safety analysis of three randomised, double-blind, placebo-controlled, phase III studies. Int $\mathrm{J}$ Clin Pract. 2013;67(7):619-32.

23. British Medical Association, Royal Pharmaceutical Society. British National Formulary 71st edition. Joint Formulary Committee. London: British Medical Association; 2016.

24. Astellas. Mirabegron. IMS Country Retail Sales Audit from March 2016. UK Market Shares for HEOR. Data on file. 2016
25. Arlandis-Guzman S, Errando-Smet C, Trocio J, Arumi D, Rejas J. Cost-effectiveness analysis of antimuscarinics in the treatment of patients with overactive bladder in Spain: a decision-tree model. BMC Urol. 2011;11:9.

26. Astellas. Mirabegron. Mirabegron cost-effectiveness model for the UK. Technical report. Data on file. 2016.

27. Office for National Statistics. Earnings (inflation adjusted) have risen by $62 \%$ since 1986 . http://webarchive.nationalarchives.gov. uk/20160105160709/http:/www.ons.gov.uk/ons/rel/lmac/ earnings-in-the-uk-over-the-past-25-years/2012/sty-payover-25-years.html/. Accessed 19 Jan 2017

28. Briggs AH, Weinstein MC, Fenwick EA, Karnon J, Sculpher MJ, et al. Model parameter estimation and uncertainty: a report of the ISPOR-SMDM Modeling Good Research Practices Task Force6. Value Health. 2012;15(6):835-42.

29. National Institute for Health and Care Excellence. Urinary incontinence in women: management. Clinical guideline. London: NICE; 11 September 2013. https://www.nice.org.uk/guidance/ cg171/resources/urinary-incontinence-in-women-management35109747194821/. Accessed 1 July 2016.

30. NHS South Devonshire. Private patient and overseas visitor price list, effective from 1st of April-31st March 2016. http://www. torbayandsouthdevon.nhs.uk/uploads/23968.pdf. Accessed 18 May 2016.

31. Incontinence Direct UK: LILIFORM Large Shaped Pads. http:// www.incontinencedirect.co.uk/ladies-incontinence-products/ disposable-products/LILFORM-Large-Shaped-Pads/. Accessed 1 July 2016. 